\begin{tabular}{c} 
International Journal of Dental Research, 5(1)(2017) 26-29 \\
International Journal of Dental Research \\
Website: $\begin{array}{c}\text { ww. sciencepubco.com/index.php/IJDR } \\
\text { doi: } 10.14419 / \text { ijdr.v5il.7390 } \\
\text { Case report }\end{array}$ \\
\hline
\end{tabular}

\title{
Oral focal mucinosis of gingiva - a rare case report and review of literature
}

\author{
Chandini dabbiru ${ }^{1 *}$, Raghavendra $\mathrm{MN}^{2}$, Kishore Moturi ${ }^{3}$, Govind Rajkumar $\mathrm{N}^{4}$ \\ ${ }^{1}$ Post Graduate Student, Department Of Oral Medicine And Radiology, Vishnu Dental College, Bhimavaram, Andhra Pradesh, India \\ ${ }^{2}$ Reader, Department Of Oral Medicine And Radiology, Vishnu Dental College, Bhimavaram, Andhra Pradesh, India \\ ${ }^{3}$ Professor, Department of Oral And Maxillofacial Surgery, Vishnu dental college, Bhimavaram, Andhra Pradesh, India \\ ${ }^{4}$ Prosessor and head of department, Department Of Oral Pathology, Vishnu dental college, Bhimavaram, Andhra Pradesh, India \\ *Corresponding author E-mail:dr.chandini29@gmail.com
}

\begin{abstract}
Oral focal mucinosis (OFM) is a rare soft-tissue lesion of unknown etiology. Clinically it appears as asymptomatic round lesions and histologically, characterized by focal myxoid degeneration of connective tissue with presence of stellate shaped fibroblasts which were also evident in the present case. This case report stresses on the fact that diagnosis of OFM is almost impossible hence diagnosis should be confirmed by histopathological examination following incisional or excisional biopsy. Through this article we present a rare case of one such lesion on the gingiva and enumerate the most characteristic and myxomatous lesions. Thus though rare, OFM must be considered in the differential diagnosis of soft tissue overgrowths in oral cavity. Here, we describe the clinical and histopathological presentation and subsequent management of OFM in a female patient.
\end{abstract}

Keywords: Gingival Growth; Electro Cautery; Stellate Shaped Fibroblasts

\section{Introduction}

Oral focal mucinosis (OFM) is an unusual clinicopathological entity which is considered to be the oral counterpart of cutaneous focal mucinosis and cutaneous myxoid cyst (Soda et al.1998). Oral focal mucinosis (OFM) was described in the year 1974 by Tomich and in the year 1996 Johnson and Helwig described it as an asymptomatic dome-shaped skin nodule, frequently seen on the face, trunk, or extremities, and termed it as cutaneous focal mucinosis (Lima et al.2008). Cutaneous focal mucinosis affects both sexes, but women aged 11-40 years have a higher prevalence. Tomich has reported 8 cases as oral counterpart of cutaneous focal mucinosis (Ena et al.2013).

Oral focal mucinosis is a rare soft-tissue lesion of unknown etiology which is characterized by a focal myxoid degeneration of connective tissue. The lesion occurs predominantly in adults during the fourth or fifth decade of life. Oral focal mucinosis shows a 2:1 female-to-male predilection (Neto et al.2014). Clinically, it is most commonly found on the gingiva and presents as a painless, sessile or pedunculated mass. The mucosa overlying bone looks to be particularly vulnerable. The lesions appear similar in colour when compared with adjoining mucosa (Joshi et al.2015).

\section{Case report}

A 45-year-old female patient reported to our outpatient department with a chief complaint of growth in her upper front teeth region since 6 months. The growth was initially peanut sized and gradually increased to attain its present size. The past medical history was non-contributory. On general examination, all the vital signs were within the normal range. The patient was systemically healthy having no adverse habits.

On intra oral examination, a painless, firm and fibrous gingival overgrowth which was roughly oval in shape measuring approximately $(1 \mathrm{~cm} \times 1.3 \mathrm{~cm} \times 0.5 \mathrm{~cm})$ located in the labial aspect of 13,14 region (Fig.1a\&b). Growth was well demarcated, pedunculated, smooth and had well defined borders extending antero-posteriorly from distal aspect of 12 to mesial aspect of 14 and superoinferiorly extending $1 \mathrm{~cm}$ from alveolar mucosa to marginal gingiva. 


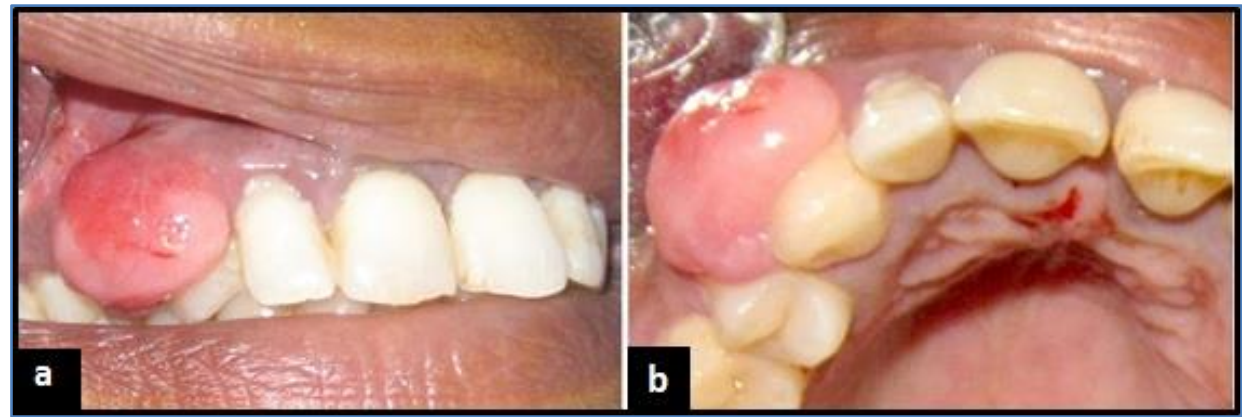

Fig. 1: (A \&B) Clinical Photograph of Oral Focal Mucinosis Involving the Right Maxillary Canine Region.

The lesion appeared reddish in colour which does not resemble adjacent mucosa. There was no history of trauma, bleeding and pus discharge. There was moderate amount of calculus present in relation to 12,13 with periodontal pocket evident in between 12 13 and 13-14, grade, I mobility in relation to $12,13,14$. Pulp vitality test was done for 12,13,14 and all tooth responded to vitality test. Generalised gingival recession, mild attritions in relation to $36,37,46,47$ and decayed teeth in relation to 38,48 were also evident.

Based on the history and clinical examination, a provisional diagnosis of irritational fibroma was given and a differential diagnosis of pyogenic granuloma and peripheral giant cell granuloma were considered.
Routine laboratory investigations revealed within normal limits. The intraoral periapical radiograph revealed mild vertical interdental bone loss between 13 and 14and horizontal interdental bone loss between 12 and 13 with decrease in interdental bone height, which is approximately $2.5-3 \mathrm{~mm}$ below CEJ. There were no periapical changes with intact lamina dura and widening of periodontal ligament space is present at the apical third of root of 14 (Fig .2).

A thorough scaling and root planning was done to remove local irritants and observed for three weeks. There was no reduction/shrinkage in the dimensions of growth following scaling and root planning. With patient's consent, a surgical excision of the lesion was done under local anaesthesia by using electro cautery procedure (Fig . $3 \mathrm{a \& b}$ ), Operated area was debrided and periodontal dressing (Zinc oxide eugenol pack) was placed.

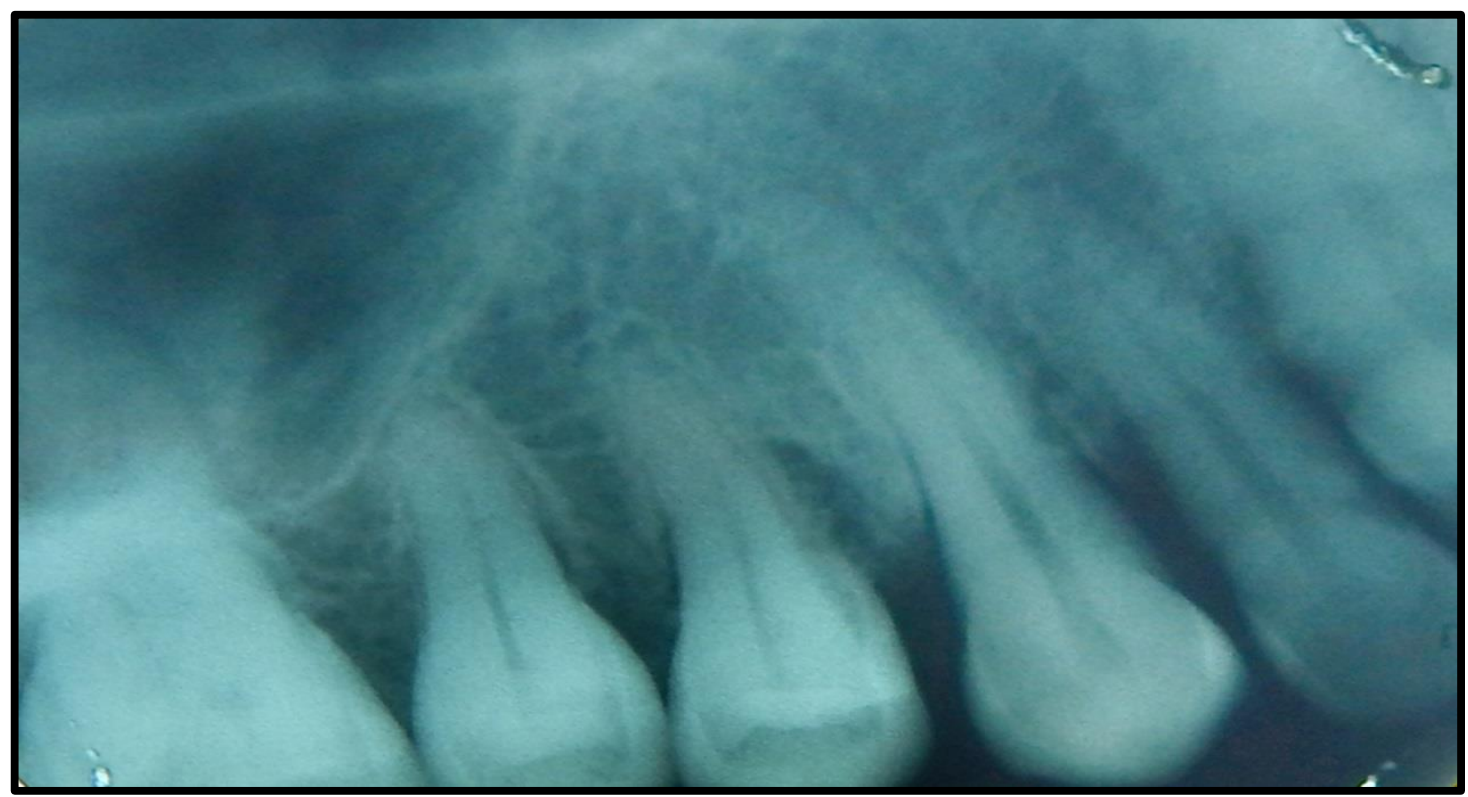

Fig. 2: Intra Oral Periapical Radiograph Showing Mild Vertical Interdental Bone Loss Between 13 and 14 and Horizontal Interdental Bone Loss between 12 and 13.

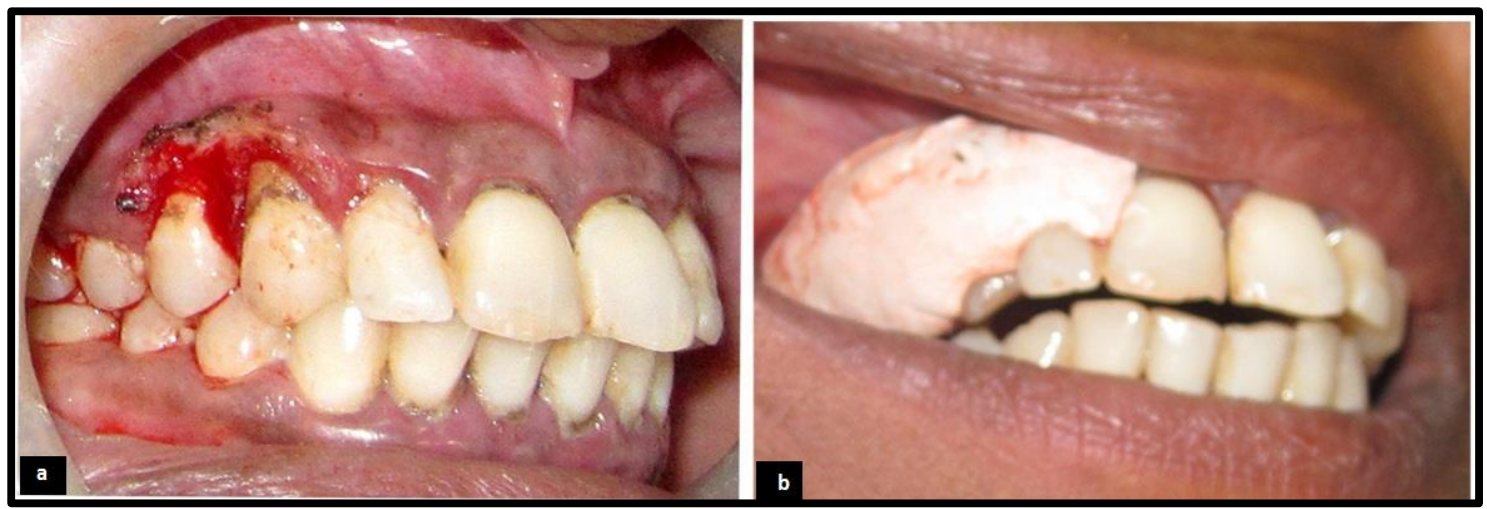

Fig. 3: (A) Surgical Excision of Lesion Done Using Electrocautery (B) Periodontal Pack was Placed after Excision. 
The excised lesion was stored in $10 \%$ formalin and sent for histopathological examination (Fig. 4). After a week, dressing was removed and healing by secondary intention was observed.

Microscopic examination of the H\&E stained soft-tissue section revealed fibrocellular connective tissue composing haphazardly arranged thick bundles of thin, delicate and wavy collagen fibres intermixed with myxoid areas. The myxoid areas were discrete at some locations. Stellate shaped fibroblasts and ovoid cells were evident. Diffuse mild chronic inflammatory infiltrate predomi- nantly plasma cells and few mast cells were also appreciated. At the periphery of the lesion, dense bundles of collagen were also seen (Fig. 5).

Based on these histologic features a final diagnosis of Oral Focal Mucinosis was given.

The patient was followed up periodically where there was no recurrence observed at 6 month follow-up (Fig. 6).

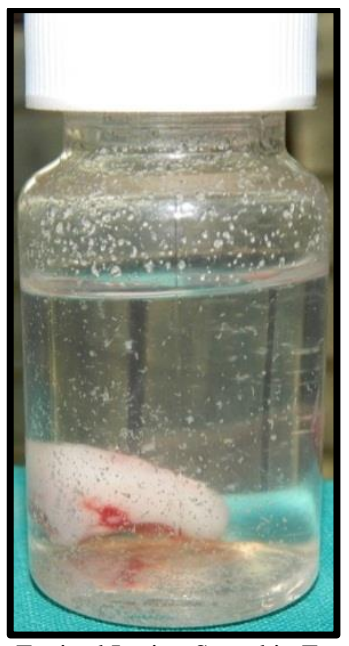

Fig. 4: Excised Lesion Stored in Formalin.

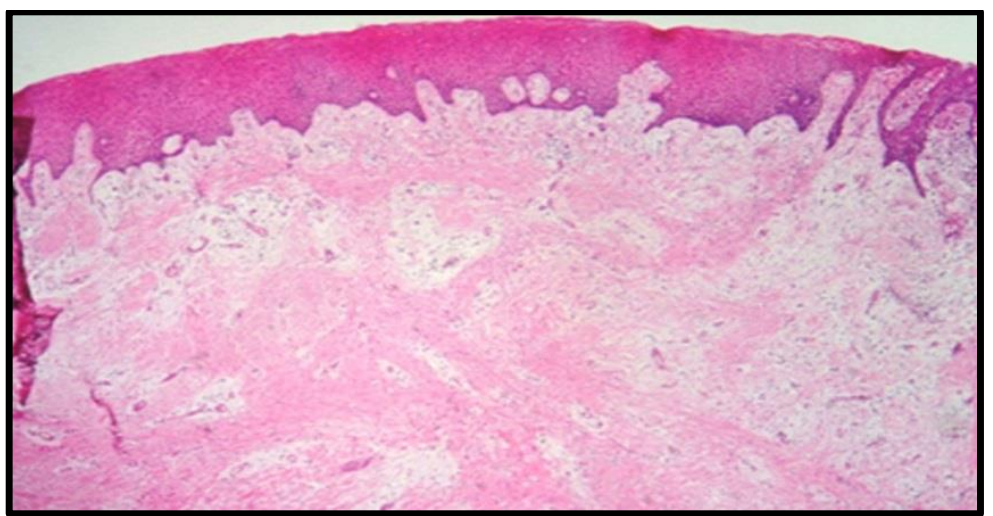

Fig. 5: Microscopic Examination Showing Fibrocellular Connective Tissue with Stellate Shaped Fibroblasts.

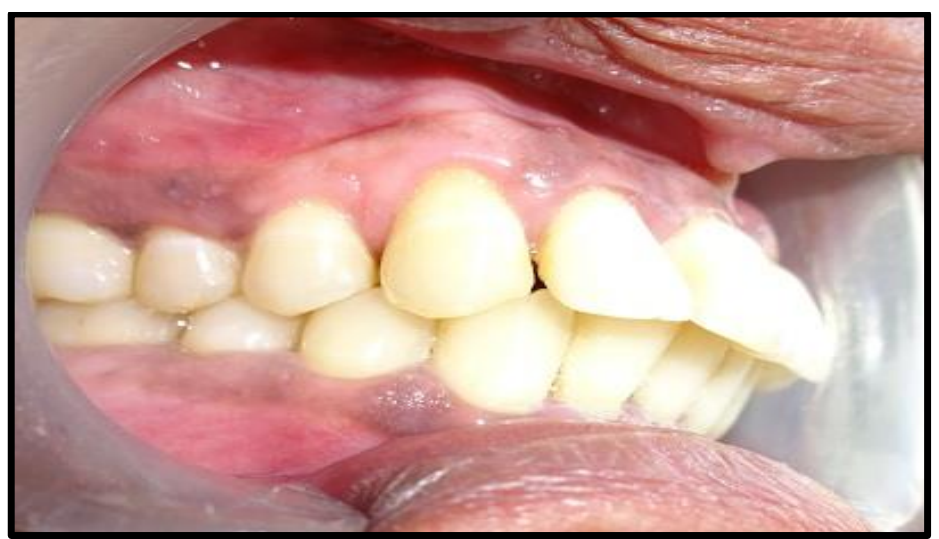

Fig. 6: Post Operative photograph which Showed No Signs of Recurrence at 6 Month Follow Up.

\section{Discussion}

Oral focal mucinosis(OFM) is a rare soft-tissue lesion of unknown etiology (Iezzi et al. 2001).Review of literature revealed that a case-series was reported by Tomich where the lesions were found mostly on the gingiva, alveolar mucosa, and tongue, and showed no apparent site predilection (Tomich. et al.1974). Oral focal mu- cinosis (OFM) occurs predominantly in females and adults with the most common site being gingiva, which was also evident in our case (Lima et al. 2008).

The etiology of focal mucinosis is unknown. Trauma does not appear to be a factor in either the oral or the cutaneous lesions. Likewise, the pathogenesis is unclear; however, Johnson and his co-worker have suggested that there is an overproduction of hya- 
luronic acid by the fibroblasts at the expense of collagen production. Therefore, increased and, indeed, an abnormal overproduction of hyaluronic acid by fibroblasts may well be responsible for the development of focal mucinosis (Tomich et al. 1974). The classical clinical presentation of the lesion is as an asymptomatic, soft to firm, sessile or pedunculated mass with a smooth surface (Rambhia et al. 2016).

A slight similarity is also seen in our case where soft tissue lesion was well demarcated, pedunculated, asymptomatic which is present on gingiva. If the lesion is untreated, there would be complications like mobility and exfoliation of offending tooth. The surgical wound healed satisfactorily and no reports of any complication or recurrence since 6 months.

Clinically, Irritational fibroma could be differentiated from pyogenic granuloma, which is an inflammatory hyperplastic lesion which develops as a response to local injury or chronic irritants like calculus, in which the granulomatous stage appears dark red, asymptomatic, soft and spongy on palpation and bleeds easily(Agarwal et al. 2016). Furthermore, it is differentiated from peripheral giant cell granuloma, which is bluish than red to pink, with mandible affected slightly more often than the maxilla (Afsaneh et al. 2016).

Histologically, pyogenic granuloma usually presents with granulation tissue in a delicate fibrillar stroma with inflammatory cells and proliferating capillaries and endothelial cells. Usually, the duration of the tumor expresses the extent of vascularity and fibrosis (Arunmozhi et al. 2016). Peripheral giant cell granuloma contains non encapsulated highly cellular mass with abundant multinucleated giant cells dispersed throughout within hemorrhagic background, chronic inflammatory cells, neutrophils, fibroblasts (Adlakha et al. 2010). While the OFM lesion contains a wellcircumscribed, localized area of myxoid connective tissue comprising of ovoid and stellate fibroblasts in an acidophilic stroma. Fibroblasts contain a small amount of cytoplasm and may have been delicate fibrillate processes extending into the surrounding matrix (Lee et al. 2012).

Microscopic examination of our case showed a Stellate shaped fibroblasts and ovoid cells which are intermixed with myxoid areas.

The consensus for treatment of oral focal mucinosis is complete surgical excision of the lesion. Recurrence of oral focal mucinosis has not been reported in the literature (Neto et al. 2014). In the present case also the patient was reviewed after a period of 6 months where the patient had no recurrence of lesion.

\section{Conclusion}

Oral focal mucinosis is a rare lesion wherein most of the cases are present on gingiva. Due to its similar appearance to that of other soft-tissue lesions of gingiva we tend to get confused to arrive at a correct diagnosis. Most importantly, Oral focal mucinosis should be considered under differential diagnosis of gingival enlargements. It can be treated by simple excision, rarely recurs upon surgical removal and has a good prognosis.

\section{References}

[1] Soda G, Baiocchini A, Bosco D, Nardoni S, Melis M (1998) Ora focal mucinosis of the tongue. Pathology Oncology Research. 4:304-307. https://doi.org/10.1007/BF02905222.

[2] Lima AAS, Machado MAN, Martins WD, Grégio AMT, Dirschnabel AJ, Mattioli TMF (2008) Oral focal mucinosis. Quintessence Inernational. 39:611-615.

[3] Ena S, Nadellamanjari, Chatterjeeanirban, Ramesh A (2013) Oral Focal Mucinosis: A Rare Case Report of Two Cases. Ethiopian Journal of Health Sciences. 23(2):178-182.
[4] Neto J, Sendyk M, Uchida L, Nunes F, de Paiva J (2014) Oral focal mucinosis associated with surgically assisted rapid maxillary expansion. American Journal of Orthodontics and Dentofacial Orthopedics. 145(4):534-538. https://doi.org/10.1016/j.ajodo.2013.02.035

[5] Joshi C, Dani N, Mahale S, Patel N (2015) A case of oral focal mucinosis of gingiva: Lesion in disguise. Journal of Indian Society of $\begin{array}{lll}\text { Periodontology.19 (5):586. } \quad \text { https://doi.org/10.4103/0972- } & \end{array}$ 124x.157874.

[6] Iezzi G, Rubini C, Fioroni M, Piatelli A (2001) Oral focal mucinosis of the gingiva: Case report. Journal of Periodontology. 72:11002. https://doi.org/10.1902/jop.2001.72.8.1100.

[7] Saito I, Ide F, Enomoto T, Kudo I (1985) Oral focal mucinosis. Journal of Oral and Maxillofacial Surgery. 43:372-4. https://doi.org/10.1016/0278-2391(85)90259-9.

[8] Tomich CE. Oral focal mucinosis (1974) A clinicopathologic and histochemical study of eight cases. Oral Surgery Oral Medicine Oral Pathology .38:714-24. https://doi.org/10.1016/00304220(74)90392-2.

[9] Rambhia KD, Khopkar US (2016) Verrucous oral focal mucinosis. Indian Journal of Dermatology, Venereology and Leprology. 82:330-2. https://doi.org/10.4103/0378-6323.174384.

[10] Agarwal N, Kumar D, Vaish A, Anand A (2016) A Rare Case of Pyogenic Granuloma with a Natal Tooth. Journal of Clinical and Diagnostic Research : https://doi.org/10.7860/jcdr/2016/23040.8701

[11] Afsaneh N, Alireza E, Parisa J, and Zahra E (2016) A Review and Report of Peripheral Giant Cell Granuloma in a 4-Year-Old Child. Case Reports in Dentistry, Article ID 7536304, 4 pages.

[12] Arunmozhi U, Priya RS, Kadhiresan R, Sujatha G, Shamsudeen-SS SM (2016) A Large Pregnancy Tumor of Tongue - A Case Report. Journal of Clinical and Diagnostic Research : 10(10):ZD10-ZD12. https://doi.org/10.7860/jcdr/2016/19869.8661.

[13] Adlakha V K, Chandna P, Rehani U, Rana V, Malik P (2010) Peripheral giant cell granuloma. Journal of Indian Society of Pedodontics and Preventive Dentistry. 28:2936 https://doi.org/10.4103/0970-4388.76161.

[14] Lee JG, Allen G, Moore L, Gue S (2012) Oral focal mucinosis in an adolescent: a case report. Australian Dental Journal. 57:90-2. https://doi.org/10.1111/j.1834-7819.2011.01649.x. 